\title{
LA ADQUISICIÓN DEL ASPECTO. CONSIDERACIONES DIDÁCTICAS PARA EL AULA DE ELE
}

\author{
LuCía QuintANA HERNÁNDEZ \\ Universidad Pablo de Olavide \\ Investigaciones de Lingüística Aplicada \\ liquiher@upo.es
}

\begin{abstract}
Resumen
Recientes estudios acerca de la distribución de los morfemas de tiempo y aspecto gramatical han puesto de manifiesto que tanto el aspecto léxico o Aktionsart como el aspecto predicacional influyen en la elección del pretérito imperfecto o el indefinido por parte de los aprendices de español como segunda lengua (Andersen, 1986; Ayoun y Salaberry, 2005; Díaz, 2006; González, 2005; Güell, 2008; Salaberry y Shirai, 2002, entre otros). Con el fin de seguir indagando en torno a la idea de que el aspecto léxico influye en la selección del pasado por parte de los alumnos de español, vamos a hacer primero una revisión del concepto de aspecto teniendo en cuenta la distinción entre aspecto gramatical, aspecto léxico y aspecto predicacional. Seguidamente, nos centraremos en los resultados de los diferentes experimentos llevados a cabo con aprendices de español teniendo en cuenta la hipótesis del aspecto según la cual el aspecto léxico influye en la selección de la morfología verbal. Luego veremos los resultados de los experimentos que además de la influencia del aspecto léxico en la selección de la morfología verbal, proponen la influencia del aspecto predicacional y del contexto discursivo. Para finalizar, presentaremos algunas implicaciones didácticas que se desprenden de lo expuesto en relación con la adquisición del aspecto.
\end{abstract}

PALABRAS CLAVE: Aktionsart, aspecto gramatical, adquisición, enseñanza, aprendizaje

\begin{abstract}
Recent studies on the acquisition of Spanish verbal morphology have shown that both the Aktionsart or lexical aspect and the predicational aspect influence the selection of the imperfecto/indefinido verbal morphology by Spanish learners (Andersen, 1986; Ayoun y Salaberry, 2005; Díaz, 2006; González, 2005; Güell, 2008; Salaberry y Shirai, 2002, among others). The aim of this paper is to review the theory of aspect bearing in mind that there are different kinds of aspect: lexical aspect, grammatical aspect and predicational aspect. First, we will focus on the results obtained in the different experiments whose hypothesis was to show that the lexical aspect influences the selection of the verbal morphology, i.e. the aspect hypothesis. Second, and in addition to the experiments that propose the primacy of the lexical aspect, we will also see the results of the experiments that propose the relevance of the predicational aspect and the contextual aspect in the acquisition of the verbal morphology. Finally, we will discuss some didactic considerations in relation to the acquisition of aspect.
\end{abstract}

KEY WORDS: Aktionsart, grammatical aspect, acquisition, teaching, learning

\section{Introducción}

Es bien conocida la dificultad que los aprendices de español muestran durante las diferentes etapas de adquisición del contraste de los pasados, especialmente del contraste entre 
el imperfecto y el indefinido. Por ello, tanto profesores de lengua como investigadores en el campo de la adquisición de segundas lenguas seguimos indagando en la comprensión de esta distinción a nivel teórico, así como en el análisis de datos experimentales, y por supuesto, también continuamos diseñando materiales didácticos que faciliten al alumno el aprendizaje de estas formas morfológicas propias del español. En las últimas décadas se ha puesto de manifiesto la importancia de los diferentes tipos de aspecto (aspecto gramatical, aspecto léxico y aspecto predicacional) en la adquisición de dicho contraste de tal manera que parece necesaria una revisión de los materiales que se usan en el aula de español a la luz de los datos obtenidos en diferentes experimentos en relación con la adquisición de la morfología verbal. El objetivo de este trabajo es primero revisar la noción de aspecto frente a la de tiempo a la luz de las diferentes propuestas teóricas, y segundo presentar los hallazgos más relevantes en el campo de la adquisición de la morfología verbal, concretamente los datos que avalan la hipótesis de la primacía del aspecto léxico en la adquisición de dicha morfología. Para ello primero se presentará el estado de la cuestión a nivel teórico y después se presentarán los datos que apoyan esta hipótesis así como los de otras existentes en el terreno dedicado a la adquisición del aspecto gramatical. El propósito será observar los datos sacados de los múltiples experimentos llevados a cabo al respecto, con el empeño posterior de proponer algunas medidas didácticas rentables a la hora de conseguir agilizar el proceso de adquisición del citado contraste.

\section{Morfología verbal: tiempo y aspecto}

Como sabemos, los morfemas verbales del español manifiestan tanto tiempo como aspecto, de tal manera que con dichos morfemas indicamos por un lado la relación temporal deíctica entre dos intervalos de tiempo (tiempo) y por otro lado la relación temporal no deíctica que enfoca las características internas del evento en cuestión, según sea la perspectiva del emisor del enunciado (aspecto). Esta última es la definición más extendida del aspecto gramatical. Cuando hablamos de tiempo nos referimos a los parámetros de anterioridad, posterioridad y simultaneidad mientras que cuando hablamos de aspecto gramatical nos referimos a los parámetros de acotación fijados o no fijados para el evento en cuestión: perfectividad e imperfectividad, básicamente. Si bien a nivel teórico se ha considerado tradicionalmente que la distinción imperfecto/indefinido es temporal (Bello, 1981; Rojo y Veiga, 1999, entre otros), también se ha propuesto que dicho contraste es aspectual (García Fernández, 1998, entre otros). De acuerdo con la propuesta de Bello (1981), el indefinido es el pretérito por excelencia y todos los otros pretéritos tienen una relación de orden cronológico con éste: el pluscuamperfecto es el antepretérito, el imperfecto el copretérito y el condicional el pospretérito. Si bien muchos ejemplos son claramente explicados con esta propuesta, muchos otros quedan sin explicación a la luz de este supuesto, como nos muestra García Fernández (1998) en el siguiente ejemplo:

\section{(1) Juan nos contó que María estaba triste el día de su boda.}

El marcador temporal el día de su boda hace que el imperfecto se interprete con valor de anterioridad, no simultaneidad, con respecto al indefinido que aparece en la oración principal. Curiosamente, las predicciones llevadas a cabo con el pluscuamperfecto y con el condicional se cumplen incluso cuando se le añade dicho marcador temporal. 
(2) Juan nos contó que María había estado triste el día de su boda. (anterioridad)

(3) Juan nos contó que María estaría triste el día de su boda. (posterioridad)

De igual forma, la introducción de una cláusula subordinada hace que nuevamente el imperfecto deje de manifestar simultaneidad con el verbo principal.

(4) Juan nos contó que María estaba triste cuando se casó.

Es imposible que María estuviera triste cuando Juan estaba contando la historia, como cabría esperar si el imperfecto indica simultaneidad con el indefinido de la oración principal. La interpretación de este enunciado pone de manifiesto que la relación de temporalidad entre estaba y contó no puede ser de simultaneidad sino de anterioridad. A pesar de que ciertamente el imperfecto deja de ser copretérito en relación con el verbo principal en (4), sí que manifiesta simultaneidad con el pretérito de la cláusula subordinada. Queda claro pues, que la distinción temporal nos permite explicar la distinción imperfecto/indefinido en múltiples ocasiones pero no en todas. Esto parece indicar que posiblemente es acertado ir tras la pista del aspecto gramatical para explicar la distinción entre el imperfecto y el indefinido.

Como ya hemos dicho, García Fernández (1998) piensa que el contraste entre estos dos tiempos verbales es aspectual y que por lo tanto la diferencia entre el indefinido y el imperfecto radica en que el uso del imperfecto indica estados, acciones y eventos en proceso, mientras que el indefinido indica estados, acciones y eventos puntuales que por lo tanto pueden enfocar tanto el comienzo como el final del estado, acción o evento. Así pues, el uso del imperfecto en (1) indica que al emisor de dicho enunciado le interesa el estado de María en aquel momento sin necesidad de fijarse en el principio o final del mismo.

Además de las dos propuestas que acabamos de revisar, también se considera que una importante distinción entre el imperfecto y el indefinido viene dada por la estructura discursiva, de tal manera que el imperfecto se utiliza para describir el fondo contextual de la narración mientras que el indefinido se utiliza para expresar el foco o los sucesos que hacen progresar la narración (Matte Bon, 1992), como vemos en el siguiente ejemplo:

(5) Eran las doce y llovía a cántaros cuando de repente sonó el teléfono, levanté el auricular y escuché su voz. Era mi novio.

Como vemos en (5), se utiliza el imperfecto para contextualizar el fondo de un relato. El indefinido introduce el foco de la acción, que en este caso podría ser el comienzo de cualquier relato de detective. Por lo tanto, podríamos decir que el aspecto gramatical presenta una clara función discursiva en la estructura narrativa.

En este trabajo vamos a considerar la propuesta de distinción aspectual, teniendo en cuenta que la categoría aspecto engloba el aspecto gramatical, el aspecto léxico, Aktionsart o modo de acción de cada entrada léxica, y el aspecto predicacional que tiene en cuenta tanto la entrada léxica como la delimitación llevada a cabo por el argumento interno. A ello se añade, como acabamos de ver, el valor que el enunciado manifieste en el discurso, de tal manera que el imperfecto se usa para mostrar el fondo descriptivo de la narración mientras que el indefinido se usa para manifestar en orden cronológico los eventos que muestran el foco narrativo (Labov, 1972). Todos estos valores aspectuales se combinan para permitir la 
expresión de enunciados en los que el uso de uno u otro pasado resultan aceptables al hablante nativo. Detengámonos primero en la revisión de la terminología para posteriormente poder explotarla adecuadamente en nuestras clases de español, especialmente en aquellos niveles donde el buen uso de la gramática es esencial.

\section{Aspecto}

Detengámonos en la noción de aspecto. Imaginemos por un momento que somos testigos de un asalto a un banco. Cuando se nos llamara a declarar lo que habíamos visto utilizaríamos las marcas morfológicas que mejor se adecuaran a la perspectiva que quisiéramos dar sobre los hechos acontecidos en un pasado relativamente reciente. Como hablantes nativos echaríamos mano de los múltiples recursos que nos permite el español para hablar del pasado desde nuestra propia óptica. Como ya sabemos, además de valores temporales propiamente dichos (anterioridad, simultaneidad y posterioridad), las marcas morfológicas verbales cuentan con valores aspectuales gramaticales que indican punto de vista. Los valores temporales nos permitirán relacionar el momento de habla con el momento en el que sucedieron los hechos, como hemos dicho. A esos valores temporales se añaden los valores aspectuales que describen las características internas de un evento desde nuestra propia perspectiva, de tal manera que si utilizamos el imperfecto estaremos situándonos en la parte interna del suceso porque no nos interesan ni el principio ni el fin, mientras que si utilizamos el indefinido estaremos situándonos en el principio o el fin de dicho evento. Así, como testigo ocular alguien podría dar el siguiente testimonio sobre el supuesto asalto:

(6) Vi a un encapuchado, no sé si era hombre o mujer, amenazó al empleado en la ventanilla y luego se puso a gritar cuando entró la policía.

Por su parte, otro testigo podría declarar lo siguiente:

(7) Fue un hombre. Estoy segura de que fue un hombre. Era muy alto y fuerte para ser una mujer. Lo escuché gritar amenazando al hombre de la ventanilla mientras entraba la policía. Fue horrible.

Tanto en (6) como en (7) vemos que ninguno de los dos interrogados se ponen de acuerdo en el uso de las marcas de indefinido e imperfecto a la hora de reconocer al ladrón. Uno de ellos parece estar seguro de que fue un hombre mientras que el otro no sabe si era hombre o mujer. El primero da por cerrada la identificación y enfoca el final del evento usando el indefinido, mientras que el otro enfoca el proceso de identificación usando el imperfecto. A esto es a lo que nos referimos cuando hablamos de perspectiva aspectual gramatical.

Observemos algunos ejemplos más:

(8) Llovió copiosamente antes de comenzar el partido.

(9) Llovía copiosamente antes de comenzar el partido.

El uso del indefinido en (8) sitúa el evento de llover antes del comienzo del partido y al mismo tiempo indica el final del evento. Por el contrario el uso del imperfecto en (9) 
igualmente sitúa el evento de llover antes del comienzo del partido y al mismo tiempo indica que posiblemente la lluvia continuara a lo largo del partido, destacando el proceso de dicho evento. El uso del imperfecto indica la parte interna del evento en cuestión pero de ninguna manera el fin del evento, mientras que el indefinido se hace eco precisamente del comienzo o del final del evento.

Como ya hemos dicho, estos ejemplos y los de García Fernández, nos hacen pensar que la propuesta de que el aspecto gramatical marca la diferencia entre el imperfecto y el indefinido de García Fernández tiene mayor poder explicativo, pero como dijimos antes, el aspecto o perspectiva sobre una determinada situación no solo se manifiesta a través de la morfología verbal. Dicho de otro modo, el aspecto no es una categoría exclusiva de la morfología verbal, sino que por el contrario, es una categoría de la que se da cuenta de manera composicional, de tal manera que tanto el significado del verbo y su estructura argumental, como la morfología verbal y la función que desempeñe el enunciado dentro de la secuencia narrativa, contribuyen a la interpretación aspectual más adecuada en el contexto. En definitiva para el cálculo del aspecto debemos tener en cuenta las siguientes variables:

- Aspecto gramatical manifestado a través de la morfología verbal. (García Fernández, 1998)

- Aspecto léxico o Aktionsart manifestado en la entrada léxica de cada predicado. (Morimoto, 1998; De Miguel, 1999)

- Aspecto predicacional manifestado de forma composicional a través de la estructura argumental del predicado. (Tenny, 1988)

- Aspecto discursivo manifestado a través de la función que cumplen las diferentes cláusulas en el texto. (Labov, 1972)

\subsection{Aspecto gramatical}

Como acabamos de ver, el aspecto puede ser manifestado a través de la morfología verbal de forma explícita en español. Esto es lo que llamamos aspecto gramatical. El aspecto gramatical nos permite una determinada perspectiva del tipo de situación presentada por el significado del verbo (aspecto léxico): el aspecto gramatical imperfectivo enfoca una parte de la situación que de ninguna manera puede ser ni el comienzo ni el fin, esto es, la parte interna del evento en proceso; el aspecto gramatical perfectivo enfoca la situación de principio a fin y el aspecto gramatical perfecto enfoca de forma crucial la parte final o resultado del evento (García Fernández, 1998, y referencias allí citadas). El aspecto imperfectivo aparece en el imperfecto y el presente de indicativo. El aspecto perfectivo aparece en el indefinido $\mathrm{y}$ en todas las formas compuestas de haber. El aspecto perfecto aparece en las formas compuestas de haber. En este trabajo vamos a fijarnos de forma muy detenida en dos formas verbales especialmente resistentes en el proceso de adquisición de los aprendices de español: el imperfecto y el indefinido, como ya hemos dicho.

\subsection{Aktionsart o aspecto léxico}

El aspecto léxico se manifiesta de forma inherente en el verbo, de forma que el mismo verbo determina si es el principio, el final o la parte interna del evento lo que se enfoca ya 
desde el propio léxico, así, aterrizar inherentemente se sitúa en el desenlace del suceso, mientras que despegar se sitúa en el punto de partida del suceso. Por su parte amar nos sitúa en la parte interna del estado. El aspecto léxico delimita el tipo de situación sobre la que posteriormente el aspecto gramatical expresará una perspectiva. Ello implica que no hay incompatibilidad entre aspecto léxico y gramatical, es decir, que un mismo verbo podrá aparecer con una u otra marca morfológica dependiendo de cual sea la perspectiva que se quiera manifestar sobre el modo de acción manifestado por el verbo. Observemos los siguientes ejemplos:

(10) Amé a Pedro con toda mi alma durante aquellos años, pero ahora todo terminó.

(11) Oí un helicóptero cuando despegaba el avión.

Tanto amar como despegar pueden recibir marcas gramaticales que enfoquen diferentes partes del evento según sea la perspectiva de la persona que emita el enunciado, de manera que en (10) el uso del indefinido indica el final del amor, mientras que el uso del imperfecto en (11) enfoca el proceso de despegue sin detenerse ni en su principio ni en su final porque lo que le interesa al emisor del enunciado es precisamente destacar un sonido que oyó mientras otro evento tenía lugar.

El aspecto léxico nos permite hacer una clasificación de los verbos atendiendo a su significado, de tal manera que el tipo de situación descrita en cualquier enunciado es determinado por el aspecto léxico. La clasificación más utilizada para llevar a cabo dicha taxonomía es la de Vendler (1967). Según esta clasificación tenemos cuatro aspectos léxicos: estados, actividades, realizaciones y logros. Los estados y las actividades se caracterizan por su falta de telicidad, esto es, por no tener una meta, como por ejemplo amar, ser, estar, caminar, cantar. Las realizaciones y logros se caracterizan por su telicidad, esto es, por tener una meta, como por ejemplo construir, llegar, despegar, aterrizar. Se podría decir que los verbos télicos (realizaciones y logros) son verbos semánticamente perfectivos mientras que los verbos atélicos (estados y actividades) son verbos semánticamente imperfectivos.

Parece, pues, que inherentemente los verbos indican si la situación será preferiblemente perfectiva o imperfectiva, esto es, centrada en el proceso o en el desenlace del evento en cuestión. Sin embargo, como ya hemos visto en (10) y (11) ello no implica que tengamos verbos que siempre aparezcan con determinadas marcas de aspecto gramatical. Veamos algunos ejemplos más:

(12) a. Caminaba durante horas antes de sentarse a escribir.

b. *Caminaba en una hora antes de sentarse a escribir.

(13) a. Caminó durante horas antes de ver el primer pueblo.

b. *Caminó en una hora antes de ver el primer pueblo.

La compatibilidad con el complemento temporal encabezado por durante y la incompatibilidad con el complemento temporal encabezado por en indica que caminar en un verbo atélico, concretamente una actividad, y como vemos en (12)-(13), este verbo admite tanto el aspecto gramatical perfectivo como el aspecto gramatical imperfectivo. Del mismo modo, el verbo télico, concretamente de logro, llegar es compatible con ambas marcas de aspecto gramatical como se observa en (14) y (15). 
(14) Cada vez que llegaba me decía lo que le habia pasado durante el día.

(15) El tren llegó a las nueve y media, como siempre.

En definitiva, vemos que aunque el propio léxico nos proporciona sus opciones aspectuales de forma inherente en cada verbo, la morfología verbal en español nos permite dar la perspectiva más acertada en cada uno de nuestros enunciados, de tal forma que obtenemos la relación aspectual entre dos intervalos de tiempo con la suma del aspecto léxico y el aspecto gramatical: el aspecto léxico nos delimita la situación denotada por el verbo mientras que el aspecto gramatical nos explicita la perspectiva sobre el evento en cuestión. En la siguiente sección veremos que el cálculo aspectual no se limita al aspecto léxico y al aspecto gramatical. La adjunción de otros complementos puede modificar las características aspectuales de los enunciados.

\subsection{Aspecto predicacional}

También podemos manifestar distinciones aspectuales a través del uso de complementos directos delimitados, de tal manera que si escribir cartas nos indica actividad en proceso de la que no nos importa ni el comienzo ni el fin, escribir un libro nos indica precisamente el resultado de esa actividad y por lo tanto nos sitúa en el resultado del evento. Así que el verbo de actividad escribir ${ }^{l}$ puede convertirse en un verbo de realización si le adjuntamos un complemento directo definido (Verkuyl, 1972; Tenny, 1988; Morimoto, 1998). Dicho de otro modo, el aspecto predicacional nos permite modificar el aspecto léxico original de una entrada léxica, de tal manera que una actividad cuyo complemento directo es delimitado se puede transformar en un verbo de realización. Veamos algunos ejemplos:

(16) *Juan corría/corrió todos los días en una hora.

(17) Juan corría todos los días durante horas.

(18) Juan corría/corrió un kilómetro en una hora.

Como podemos apreciar en (16)-(18), el comportamiento del verbo correr es desigual si le adjuntamos el complemento directo definido un kilómetro. El verbo de actividad correr no permite la adjunción del sintagma preposicional en una hora, como vemos en (16), puesto que la situación denotada por este verbo de ninguna manera aparece delimitada, como pone de manifiesto la posibilidad de adjuntar el complemento durante horas en (17). Sin embargo, la complementación del verbo por parte del sintagma nominal un kilómetro en (18) permite la adjunción del citado sintagma preposicional, lo cual demuestra que en este caso estamos ante un verbo télico, concretamente una realización.

1 Según uno de los evaluadores anónimos de este trabajo, es discutible que el significado básico de escribir sea una actividad y no una realización, en cuyo caso obtendríamos la actividad al prescindir del complemento directo delimitado. Sin embargo, y precisamente teniendo en cuenta que los complementos directos de este verbo no son obligatoriamente delimitados, esto es, podemos decir que un escribiente puede escribir cartas durante horas, sin por ello estar hablando de una carta concreta, pensamos que este predicado es en origen una actividad y no una realización, aunque nuestro conocimiento del mundo nos indica que para escribir cartas uno tiene que completar cada una de ellas. 
Así pues, como hemos comprobado, además del aspecto léxico, debemos tener en cuenta los argumentos del verbo a la hora de computar los valores aspectuales. Aunque no es una cuestión en la que nos detendremos en este trabajo, el carácter composicional del aspecto nos indica que también debemos prestar atención al resto de complementos temporales que se adjuntan al verbo. Una entrada léxica atélica no aparece obligatoriamente marcada por rasgos morfológicos imperfectivos, como ya hemos visto, ni tampoco por adjuntos característicos de verbos atélicos. Por el contrario, la complementación puede convertir una actividad (atélico) en una realización (télico) con el consecuente cambio en relación con la selección de otros adjuntos. En definitiva, y tal como hemos visto en (16) y (18) el uso de una u otra marca aspectual gramatical vendrá definida por la perspectiva de la situación que el hablante quiera expresar.

\subsection{Aspecto discursivo: fondo y foco}

Como ya hemos dicho, también podemos manifestar diferencias aspectuales a través de la estructura discursiva, de tal manera que en la narración de una serie de eventos, algunas cláusulas nos servirán para relatar la sucesión de eventos en orden cronológico, mientras que otras nos servirán para contextualizar el fondo de los hechos. Las primeras constituyen lo que en la literatura se conoce como foco narrativo y las segundas constituyen el fondo narrativo (Labov, 1972). A su vez, juntas constituyen la tradicional dicotomía que caracteriza los textos narrativos.

Como dice Labov, las oraciones que constituyen el foco del texto dan al oyente el esqueleto de la narración y constituyen el eje temporal del texto narrativo. Las demás cláusulas constituyen el fondo y su función es dar al oyente otra información adicional. Por un lado, el foco lo constituirán las oraciones que sigan el orden cronológico de los hechos que tuvieron lugar (Labov, 1972); que además también constituyan una respuesta a la pregunta hipotética ¿qué pasó después? (von Stutterheim y Klein, 1989); que tengan verbos cuyo aspecto gramatical sea perfectivo, habitualmente el pretérito indefinido. Por otro lado, el fondo lo constituirán las oraciones que contengan verbos cuyo aspecto gramatical sea imperfectivo, habitualmente el pretérito imperfecto. Estas oraciones habitualmente responden a preguntas del siguiente tipo: ¿cómo era?, ¿qué llevaba?, etc.

Como podemos comprobar, hay múltiples formas de manifestar distinciones aspectuales, lo cual nos indica que este es un fenómeno lingüístico composicional que muy difícilmente puede ser simplificado para que los aprendices de español como segunda lengua puedan aprender unas pocas reglas que aplicar para diferenciar el imperfecto del indefinido. En el siguiente apartado analizaremos algunas de las propuestas más relevantes en relación con la adquisición de la categoría semántica denominada aspecto, entendiendo por aspecto el conglomerado de aspectos que acabamos de revisar: aspecto gramatical, aspecto léxico, aspecto predicacional y aspecto discursivo.

\section{Adquisición del aspecto}

Si bien es cierto que todas las lenguas presentan recursos para expresar el significado atribuido a las variedades aspectuales ya citadas, no todas las lenguas cuentan con los mismos recursos, sobre todo en el nivel del aspecto gramatical. La marca morfológica de imperfecto 
del español es una de estas formas que no todas las lenguas tienen, de ahí la complejidad que se le plantea al aprendiz a la hora de discernir entre el uso de uno u otro pretérito. El aprendiz anglohablante, por ejemplo, no cuenta con el contraste aspectual perfectivo/imperfectivo sino perfectivo/progresivo, y por tanto tampoco cuenta con el contraste morfológico imperfecto/ indefinido, de tal manera que para dar cuenta del significado característico del imperfecto el inglés usa el pasado progresivo como vemos a continuación:

(19) It was raining the first time I saw you.

(20) Llovía cuando te vi por primera vez.

La distinción observada en (19)-(20) es la que hace que los aprendices anglohablantes tarden un tiempo en usar tanto el imperfecto como el gerundio en español de la misma forma que los hablantes nativos. La dificultad que plantea la adquisición de estas formas es lo que ha fomentado la observación y el análisis de datos de aprendices de español, sobre todo de los anglohablantes. Sin duda, detrás de los análisis que han llevado a muchos expertos a prestar atención a la adquisición de la morfología verbal en las últimas décadas está el siguiente interrogante: ¿Por qué nuestros alumnos tardan tanto en adquirir la distinción imperfecto/indefinido?

Por fortuna, en las últimas décadas se han producido importantes avances en la comprensión de los procesos de adquisición de la morfología verbal. Diferentes análisis de datos de aprendices de distintas lenguas han puesto de manifiesto la relevancia de las variedades aspectuales en la adquisición de la morfología verbal. Si bien en los últimos años se ha disparado la investigación en torno a este tema y se han propuesto varias explicaciones desde diversos puntos de vista, una de ellas parece solaparse de forma constante en todas las hipótesis propuestas: la hipótesis de la primacía del aspecto léxico a la hora de seleccionar la morfología verbal.

Según esta propuesta (Andersen, 1986), el aspecto léxico influye en la selección del aspecto gramatical por aparte del aprendiz de segundas lenguas, de tal modo que un verbo inherentemente télico como ganar promoverá el uso del pretérito indefinido, mientras que un verbo atélico como llorar promoverá el uso del pretérito imperfecto. A pesar de ser esta la hipótesis más influyente en las investigaciones llevadas a cabo hasta el momento, otros análisis han puesto de manifiesto que el aspecto léxico no es el único factor influyente en la selección del aspecto gramatical. De hecho parece que tanto el aspecto predicacional como el aspecto discursivo influyen también en la selección de la morfología verbal. Los datos parecen avalar múltiples hipótesis que desde nuestro punto de vista no se excluyen entre sí, aunque sí indican que debemos seguir trabajando en la comprensión de las diferentes fases del proceso de adquisición de la morfología verbal.

Como acabamos de decir, el análisis de múltiples datos recogidos de aprendices de segundas lenguas ha llevado a los investigadores a formular varias hipótesis acerca de la adquisición de la morfología verbal. A continuación vamos a revisar las más influyentes en la literatura en torno a esta cuestión.

\subsection{Hipótesis de la primacía del aspecto léxico}

A raíz de un estudio longitudinal de dos aprendices de español en un entorno natural, Andersen (1986) observa que la distribución de las marcas morfológicas verbales de indefinido 
e imperfecto responde a matices de tipo léxico-semántico, de tal forma que las clases aspectuales de Vendler (1967) parecen influir en la selección de la susodicha morfología verbal. Los datos observados muestran una clara tendencia a utilizar el indefinido con verbos télicos y el imperfecto con verbos atélicos. Los primeros datos recogidos mostraban ausencia total de marcas morfológicas del imperfecto y presencia de marcas de indefinido en el $50 \%$ de los verbos que obligatoriamente lo precisaban. La segunda recogida de datos mostraba que el porcentaje de verbos con marca de indefinido aumentaba al $88 \%$ y además aparecía el imperfecto en el $43 \%$ de los casos en los que era obligatorio. Para Andersen los datos demostraban una clara correlación entre las clases aspectuales y los morfemas verbales de imperfecto e indefinido. Según él, en las primeras etapas de adquisición las marcas morfológicas verbales codifican información aspectual léxica.

Así pues, los aprendices de español utilizan de forma inconsciente las distinciones de aspecto léxico en las primeras etapas de adquisición de tal manera que en un primer momento la morfología perfectiva del indefinido aparece primero con verbos télicos y después con verbos atélicos. Más tarde, la morfología imperfectiva del imperfecto aparece primero con verbos atélicos y posteriormente con verbos télicos. En consecuencia, Andersen propone que los aprendices de lenguas comienzan utilizando la morfología verbal perfectiva con logros (ganar, perder) y realizaciones (escribir una carta) y en etapas posteriores su uso se extiende a actividades (caminar, trabajar) y estados (amar, gustar). Más tarde, los aprendices de español comienzan a utilizar la morfología imperfectiva con estados y actividades y posteriormente con realizaciones y logros.

Con este análisis Andersen propone ocho etapas en el proceso de adquisición de la morfología verbal, aunque en realidad tan solo encuentra pruebas para demostrar cuatro etapas: desde verbos télicos a atélicos con el indefinido en las primeras cuatro fases; desde los verbos atélicos a los télicos con el imperfecto en las cuatro fases posteriores. En definitiva, su propuesta muestra una progresión en el uso de las formas gramaticales perfectivas: comienza usándose con verbos télicos y más tarde se extiende su uso con verbos atélicos. Por el contrario, la morfología verbal imperfectiva aparece con verbos atélicos en las primeras etapas para extenderse a verbos télicos en etapas posteriores.

En las últimas décadas se han seguido publicando trabajos en los que se demuestra que efectivamente los aprendices de segundas lenguas tienen en cuenta las distinciones aspectuales léxicas que acabamos de recordar a la hora de seleccionar las marcas morfológicas verbales de imperfecto e indefinido. Para llegar a esta conclusión se han realizado experimentos basados en tareas de comprensión y producción oral espontáneas y tareas de comprensión y producción escrita controladas (Hasbún, 1995; González, 2003), además de tareas de elección múltiple de frases completamente descontextualizadas (Güell, 2008).

A pesar de que los datos de los ochenta sujetos del trabajo de Hasbún (1995) no dieron los resultados esperados en relación con las fases propuestas por Andersen, sí que demuestran que decididamente el aspecto léxico influye en la selección de la morfología verbal. Por su parte, González (2003) propone que además del aspecto léxico, el aspecto predicacional influye en la selección del aspecto gramatical por parte del alumno, de tal forma que para la correcta explicación de los datos obtenidos en su experimento en torno a la distinción aspectual perfectivo/imperfectivo se debería tener en cuenta el aspecto léxico y también el aspecto predicacional. Añadir determinado argumento a un predicado puede cambiar el valor aspectual de dicho predicado, como ya hemos visto en el apartado 3.3. Según esta propuesta, 
posiblemente la concordancia observada entre el aspecto léxico y el aspecto gramatical en el uso de la morfología verbal por parte de los aprendices de español, se da precisamente en el nivel de aspecto predicacional, no en el del aspecto léxico, de tal manera que un verbo como correr, presumiblemente clasificado como actividad, aparecerá preferiblemente en imperfecto en la producción del aprendiz, mientras que correr un kilómetro, presumiblemente una realización, aparecerá en indefinido en las primeras fases de adquisición de la morfología verbal.

En un reciente experimento, Güell (2008) ha puesto de manifiesto que en ausencia de contexto incluso el hablante nativo de español se deja influir por el aspecto léxico a la hora de seleccionar el indefinido o el imperfecto. Su experimento, además de validar la hipótesis de la primacía del aspecto léxico a la hora de seleccionar la morfología verbal, señala que los hablantes nativos de español también recurren al aspecto léxico para usar las marcas morfológicas de indefinido e imperfecto en ausencia de contexto. Nosotros mismos hemos aplicado sus pruebas a más informantes, tanto nativo hablantes de español como aprendices de español como segunda lengua para verificar sus resultados y, aunque los resultados no son del todo definitivos, parece que efectivamente, tanto el aspecto léxico como el aspecto predicacional influyen en la selección de la morfología verbal en ausencia de contexto. Los datos que hemos obtenido son los siguientes:

El grupo de control de nativo hablantes (ocho sujetos) de español presenta un comportamiento mixto: la mayoría de los sujetos obedecen por completo al patrón según el cual el aspecto predicacional influye decisivamente en la selección del imperfecto o del indefinido. No obstante, dos de ellos manifiestan la prevalencia del aspecto léxico como observamos en los siguientes ejemplos:

(21) Vicente ganó/ganaba premios.

(22) El policía supo/sabía la verdad.

El uso del indefinido con el verbo de logro ganar en (21) indica que el sujeto no tiene en cuenta el complemento plural sin determinante premios que convierte a dicho verbo en una actividad. Justo lo contrario ocurre en (22) donde el sujeto no tiene en cuenta el complemento singular con determinante que transforma el estado saber en un evento télico. En cualquier caso, parece que los verbos de actividad que aparecen en la prueba de Güell (2008) (escribir, dibujar) son aquellos en los que la distancia aspectual se difumina y se produce más titubeo entre los datos de los sujetos observados. Posiblemente esto se deba al hecho de que estos predicados son realizaciones cuando aparecen con complementos delimitados como por ejemplo escribir un libro o dibujar una casa. En realidad, el hecho de que los hablantes nativos no respondan a un patrón único parece indicar que esta prueba debe ser replanteada.

Desde mi punto de vista, sería necesario ampliar la batería de ejemplos propuestos por Güell de manera que el mismo verbo apareciera más de una vez y con diferentes posibilidades atendiendo tanto al aspecto léxico como al aspecto predicacional. La muestra obtenida es demasiado escueta. Tan solo utiliza los verbos ganar, perder, encontrar, vivir, saber, fumar, escribir, recitar y dibujar en unas pocas variables combinatorias posibles. También creo que para poder concluir que el nativo hablante se ajusta a la hipótesis de la primacía del aspecto léxico a la hora de seleccionar la morfología verbal, la prueba debería haberse limitado aún más eliminando cualquier complemento directo que interfiriera en la influencia del aspecto 
predicacional. Solo en ausencia de contexto podremos realmente afirmar que el hablante nativo se deja influir por el aspecto léxico.

Por su parte el grupo de aprendices ( 9 sujetos) mostró el siguiente comportamiento: la hablante de alemán mostró un comportamiento similar al de buena parte de los hablantes nativos, esto es, prevalece el aspecto predicacional a la hora de seleccionar la morfología verbal. Sin embargo, prevalece el aspecto léxico con los verbos saber (estado) y dibujar (actividad). El hablante de polaco no responde a ninguna de las expectativas según la hipótesis de la primacía del aspecto. Uno de los siete hablantes de inglés usa el indefinido por defecto, tan solo los verbos saber y fumar aparecen con el imperfecto para este sujeto. Dos de los hablantes de lengua inglesa se dejan influir claramente por el aspecto predicacional. Los cuatro restantes manifiestan claramente influencia del aspecto léxico en la selección de la morfología verbal. Aunque ciertamente los resultados de esta prueba ponen de manifiesto el peso del significado léxico en la selección de la morfología verbal, no son concluyentes, más bien señalan la necesidad de redefinir los ejemplos de la muestra, y por supuesto complementarlos con otro tipo de pruebas contextualizadas.

Si bien concluimos que el aspecto léxico es un potente motor a la hora de seleccionar la marca verbal por parte del aprendiz de español, la pregunta que surge ante el planteamiento de Güell es si realmente la hipótesis de la primacía del aspecto a la hora de seleccionar la morfología verbal funciona también cuando presentas al alumno datos en los que explícitamente hay referencia temporal. ¿Sigue manteniendo el alumno la tendencia a usar el aspecto perfectivo con logros y realizaciones en presencia de un contexto temporal concreto? $\mathrm{Mu}$ chos de los experimentos llevados a cabo hasta el momento responden afirmativamente a este interrogante, pero ninguno de ellos lo hace de forma contundente, lo cual significa que debemos seguir diseñando nuevas pruebas que nos ayuden a entender mejor qué variedad aspectual guía la selección de las marcas morfológicas verbales por parte de nuestros alumnos.

Las manifiestas carencias del análisis de la hipótesis de la primacía del aspecto léxico nos llevan a presentar otras de las hipótesis que se manejan en la actualidad y que han surgido precisamente después de que Andersen propusiera la primacía del aspecto léxico sobre el tiempo en la adquisición de la morfología verbal de español y previsiblemente también en otras lenguas. A continuación veremos la hipótesis del tiempo por defecto y después la hipótesis del discurso.

\subsection{Hipótesis del tiempo por defecto}

Según Salaberry (2002, 2003), la hipótesis del tiempo por defecto responde a factores de procesamiento cognitivo. Según esta hipótesis, el tiempo tiene primacía sobre el aspecto en las primeras fases de adquisición de la morfología verbal. Por eso, en un primer momento, los aprendices solo marcan distinciones temporales y tan solo usan el indefinido con todo tipo de verbos. De acuerdo con esta propuesta, el indefinido es el pasado no marcado en español y por ello aparece primero, mientras que el imperfecto es el pasado marcado y por lo tanto aparece después.

Como acabamos de mostrar en los datos de uno de los sujetos analizados a la luz de los datos de Güell (2008) en el subapartado anterior, esta hipótesis tiene sentido para los aprendices de español cuya lengua materna no manifiesta la existencia de una morfología verbal similar a la del español, como es el caso del inglés. De hecho uno de los sujetos usa el 
indefinido con casi todas las formas verbales, lo cual parece indicar que todavía se encuentra en las fases iniciales de adquisición de las marcas morfológicas verbales del español. A favor de esta propuesta y en nuestra trayectoria como profesores de español, seguramente muchos hemos tenido la oportunidad de observar en nuestras clases con anglohablantes, que ciertamente al principio el alumno utiliza tan solo el indefinido en sus narraciones tanto orales como escritas. Sin embargo, a pesar de lo cierto de esta observación, creemos que esta hipótesis no excluye la hipótesis de la primacía del aspecto que hemos visto en el apartado anterior.

Como ya dijimos, la hipótesis de la primacía del aspecto léxico manifiesta que primero aparece el indefinido con verbos télicos y seguidamente se extiende su uso a verbos atélicos. No es casual que esta primera fase de la citada hipótesis se solape con la hipótesis del tiempo por defecto: primero aparecen las formas perfectivas, entre ellas el indefinido, y después las imperfectivas, pero en cualquier caso, siempre guiadas por el significado léxico del verbo. En realidad, ambas hipótesis se complementan. Puede ser que en una primera fase el aprendiz en su afán por comunicarse ciertamente tan solo procese información temporal y por ello tan solo use el indefinido como marca morfológica verbal contrastada con el presente y el futuro. Pero como los datos recogidos en los diferentes experimentos realizados demuestran, en una segunda fase de la adquisición de las marcas morfológicas verbales el aprendiz tiene en cuenta el aspecto léxico del verbo al que adjunta los morfemas.

Sin duda, sería muy interesante integrar las dos hipótesis hasta ahora presentadas para analizar de forma más detenida las primeras fases de adquisición de la morfología verbal, en particular las diferentes fases por las que pasa el aprendiz desde que comienza a utilizar supuestamente el indefinido hasta que posteriormente integra el imperfecto. Según algunos estudios, incluso en los procesos de adquisición del español como primera lengua esta marca morfológica tarda en aparecer en la producción de los niños (Álvarez, 2005). La forma de pretérito imperfecto del español es una forma verbal más sutil, llena de matices semánticos, cuyo estudio puede acercarnos más al entendimiento del procesamiento de las formas verbales por las que pasa el aprendiz de segundas lenguas. Por ello, la distinción indefinido/ imperfecto del español es tan relevante para la comprensión de los procesos de adquisición de la morfología verbal. El debate, pues, está servido, ¿qué guía la adquisición de estas marcas morfológicas?, ¿el tiempo o el aspecto léxico? A estos interrogantes se suman otras propuestas que evidencian la complejidad del aspecto y por lo tanto la complejidad manifiesta en la adquisición de la morfología verbal, concretamente la adquisición del aspecto gramatical.

\subsection{Hipótesis del aspecto discursivo}

La última propuesta de la que daremos cuenta en este trabajo es la hipótesis del discurso, según la cual los aprendices usan las formas verbales de indefinido e imperfecto para distinguir foco y fondo respectivamente. Según Hopper (1982), puesto que las distinciones aspectuales planteadas desde una perspectiva léxico-semántica no parecen estar caracterizadas de forma consistente, debemos atender a una más adecuada explicación de la función discursiva. Según esta propuesta, una vez que el aprendiz tiene en su haber las dos formas, indefinido e imperfecto, comienza a utilizarlas para distinguir lo que constituye la sucesión de hechos ordenados cronológicamente como eje temporal de la narración y lo que constituye información adicional a esos hechos acontecidos, respectivamente. 
A pesar de las diferentes premisas con las que trabajan los análisis llevados a cabo desde esta perspectiva discursiva (Lafford, 1996; Bardovi-Harlig, 1998; Güell, 1998, entre otros), los resultados se solapan con los de la hipótesis de la primacía del aspecto léxico. Los resultados de Lafford son especialmente interesantes. De los quince aprendices de español en contexto de instrucción de diferentes niveles de español, los dos estudiantes de nivel intermedio bajo no utilizan el imperfecto en su narración, tan solo utilizan el indefinido para relatar lo que corresponde al foco de la narración. Los seis estudiantes de nivel intermedio medio tampoco utilizan el imperfecto pero empiezan a utilizar el indefinido para relatar tanto los hechos que funcionan como el foco de la narración como los que corresponden al fondo de la narración. Los siete estudiantes de nivel intermedio alto ya usan el imperfecto para referir al fondo de la narración y el indefinido tanto para el foco de la narración como para el fondo de la narración, aunque esto último en menor medida.

Lejos de invalidar las hipótesis anteriormente expuestas, los resultados de este análisis manifiestan nuevamente que el aprendiz de español como segunda lengua comienza utilizando tan solo el indefinido y que posteriormente comienza a utilizar el imperfecto para referir a aquellos eventos que conforman el fondo de estructuras narrativas. Lo interesante sería examinar con detenimiento qué clases aspectuales aparecen como fondo y foco en las narraciones tanto espontáneas como escritas de estos y otros sujetos. Esta última hipótesis presupone que el aprendiz de español como segunda lengua ya ha pasado por las primeras fases de adquisición en las que todo era expresado con el indefinido. La cuestión que se plantea es en qué medida esta hipótesis y la de la primacía del aspecto léxico intervienen en el sujeto para hacer avanzar su competencia lingüística.

En resumidas cuentas, de lo dicho anteriormente se desprende que ninguna de las tres hipótesis se excluyen entre sí; por el contrario, cada una de ellas parece describir una etapa diferente del proceso de adquisición de una segunda lengua, en este caso el español:

- En un primer momento el aprendiz usa el indefinido para cualquier evento situado en el pasado. Ello parece indicar que tan solo le atribuye valores temporales a la morfología verbal en esta fase de adquisición, tal como predice la hipótesis del tiempo por defecto. Posteriormente, esta etapa se solapa con la hipótesis de la primacía del aspecto léxico ya que el indefinido aparece exclusivamente con verbos télicos y posteriormente atélicos.

- En un segundo momento y teniendo en cuenta el aspecto léxico, el aprendiz comienza a utilizar el imperfecto con predicados de estado y actividad y a medida que avanza el proceso de adquisición, el aprendiz usa las marcas morfológicas de aspecto imperfectivo con predicados de realización y logro.

- En una tercera fase, el aprendiz comienza a distinguir el foco y el fondo de una narración utilizando para ello la morfología verbal: el imperfecto para el fondo o descripción de la situación y el indefinido para el foco o sucesión de eventos en orden cronológico. El aprendiz comienza a integrar en su competencia lingüística el hecho de que el contexto delimita fuertemente los valores semánticos de la morfología verbal en español.

Lejos de suponer una respuesta definitiva al debate actualmente abierto en torno a la adquisición del aspecto gramatical, debemos seguir trabajando para desenmascarar muchos otros factores que intervienen en el proceso de adquisición de las marcas morfológicas verbales: el input al que está expuesto el aprendiz, la edad del aprendiz y la motivación, entre 
otros. Sobre todo, deben redefinirse los conceptos teóricos tales como el de clase aspectual, además de proveerse de taxonomías verbales útiles para el diseño de materiales para el aula de segundas lenguas. También deben acordarse nuevos métodos de recogida de datos por parte de los investigadores, métodos que nos sirvan para controlar los múltiples factores que intervienen en el individuo a la hora de hacer las tareas que se le imponen como medio de recoger los datos.

\section{Consideraciones didácticas}

Una serie de propuestas metodológicas se desprenden del análisis de las propuestas que acabamos de enumerar en el apartado anterior y como docentes es nuestro compromiso tener muy en cuenta estos hallazgos a la hora de diseñar nuestros materiales en clase y también a la hora de evaluar la competencia lingüística de nuestros alumnos. Si como todas las propuestas parecen evidenciar el aspecto léxico influye en la selección de la morfología verbal, debemos asegurarnos de que el input que ofrecemos en clase desde los niveles iniciales esté enriquecido con todo tipo de verbos que muestren además todo tipo de marcas morfológicas, tanto en materiales didácticos como en materiales reales. Además de proveer al aprendiz del input adecuado, creemos que es relevante integrar la distinción aspecto léxico/aspecto gramatical en nuestras lecciones gramaticales. De esta manera podemos acelerar el proceso de adquisición de la morfología verbal a través de la instrucción formal en el aula.

Si como decimos ninguno de estos hallazgos en relación con la adquisición de la morfología verbal debe pasar inadvertido, tampoco debemos olvidar la ingente cantidad de recursos que tenemos a nuestra disposición como docentes. Está en nuestras manos seleccionar cuidadosamente aquellos que contravengan la creencia inconsciente de que el aspecto léxico se corresponde unívocamente con el aspecto gramatical y evitar que los aprendices usen el imperfecto tan solo con estados y actividades y el indefinido con logros y realizaciones. Comencemos revisando algunos de estos materiales, concretamente algunos manuales de español como lengua extranjera, atendiendo especialmente a la clase aspectual léxica de los verbos que aparecen tanto en explicaciones gramaticales como en ejercicios prácticos. Dicha revisión se hará haciendo hincapié en que lo deseable es utilizar estos manuales como fuente de inspiración para la creación de nuevos materiales reales que, además de integrar la noción de aspecto léxico, también conecten con los intereses de nuestros alumnos.

Desgraciadamente, al revisar manuales de español como lengua extranjera para niveles iniciales, vemos numerosos ejemplos de ejercicios con frases descontextualizadas que más bien parecen pruebas de algunos de los experimentos de adquisición de segundas lenguas que acabamos de presentar. Veamos algunos ejemplos de los que podemos encontrar en un ejercicio cuyo enunciado pide que se complete con el verbo en el tiempo adecuado de pasado:

(23) A veces (cantar) por la calle sin ningún motivo.

(24) De vez en cuando (preparar) algún plato especial para sus invitados.

Al hecho de que los ejercicios como el anterior aparezcan completamente descontextualizadas, tenemos que añadir el que, además, la respuesta supuestamente correcta de (23) suponga indirectamente un input completamente manipulado a favor de la hipótesis de la primacía del aspecto léxico: cantar es un verbo de actividad y, como ya hemos visto, según 
la predicción de la hipótesis de la primacía del aspecto léxico, nuestro alumno relacionará de forma inconsciente este verbo con la marca morfológica de imperfecto. A esa creencia inconsciente se une el refuerzo positivo por parte de la respuesta correcta a (23): el imperfecto. Eso es precisamente lo que queremos evitar, así que sería deseable que el mismo predicado apareciera con el indefinido en el mismo ejercicio, de manera que el aprendiz también recibiera refuerzo negativo en contra de la hipótesis de la primacía del aspecto léxico.

Detengámonos en las pruebas que nos permiten distinguir el aspecto léxico de los predicados en (23) y (24). Si atendemos a una de las pruebas que distingue los predicados télicos de los atélicos en (25)-(26) observaremos que cantar permite la adjunción del complemento temporal encabezado por durante y preparar permite la adjunción del complemento temporal encabezado por en, lo cual, como hemos visto en otros ejemplos, nos permite clasificarlos como atélico y télico respectivamente.

(25) a. *Cantó en una hora.

b. Cantó durante una hora.

(26) a. *Preparó la comida durante una hora.

b. Preparó la comida en una hora.

Si esto es así y cantar es un verbo télico, presumiblemente una actividad por cuanto el evento no culmina, el aprendiz seleccionará el imperfecto como respuesta correcta, guiado por el aspecto léxico del verbo, como ya hemos dicho. Por el contrario, si preparar es una realización, el aprendiz seleccionará el indefinido erróneamente como respuesta a (24). Mientras que la respuesta correcta de (23) supone parte del input que no debemos promover en solitario en los primeros contactos del aprendiz con los pretéritos, (24) parece ser parte de un input deseable por cuanto un verbo télico aparece con imperfecto y no solo con indefinido. En cualquier caso, este tipo de ejercicios debiera plantearse en contexto para dar más información respecto al uso de la morfología verbal.

Así que con ejemplos como (23) estamos favoreciendo que la creencia inconsciente se vea verificada, mientras que con ejemplos como (24) estamos favoreciendo que el aprendiz reciba el refuerzo negativo contra dicha creencia. El ejemplo de (23) es precisamente el tipo de input que no debemos fomentar, de forma exclusiva, en clase. Por el contrario, debemos seleccionar textos ricos en multitud de verbos y marcas morfológicas verbales de manera que el input al que exponemos a nuestros alumnos sea rico en matices que les ayuden a agilizar las fases de adquisición de la morfología verbal. Nuestro objetivo debe ser siempre anular la fosilización de reglas simplificadas que relacionen el imperfecto con verbos atélicos y el indefinido con verbos télicos.

El siguiente ejemplo sacado también de un manual de español, sería otro de estos ejemplos que iría en contra de la creencia inconsciente que relaciona el aspecto léxico y el aspecto gramatical. De igual forma que en la actividad anterior, se le pide al alumno que complete la oración con el verbo en el tiempo adecuado de pasado.

(27) Cada dia (salir) de su casa a la misma hora.

Salir es un verbo de logro y sin embargo en este ejemplo el aprendiz verá que no aparece la morfología de indefinido sino la de imperfecto. Con este tipo de input pondremos a 
nuestros alumnos en disposición de entender que la morfología verbal es independiente del significado del verbo. Si bien, este podría ser un ejemplo deseable en el aula, sería mejor utilizarlo en contexto, pues así es como el nativo hablante lo entiende.

Del mismo modo debemos prestar mucha atención a los ejemplos que utilizamos para nuestras explicaciones en clase. Observemos detenidamente los que utiliza otro manual de español para explicar el uso del imperfecto:

(28) El pretérito imperfecto de indicativo describe una acción que estaba en progreso durante algún tiempo en el pasado o cuando algo sucedió:

- Almorzaba cuando llegaron.

- Sonaba el teléfono cuando abrí la puerta.

- Los soldados estaban alerta.

- Todas las puertas y ventanas crujían.

Los ejemplos además de descontextualizados por completo, muestran un alto porcentaje de predicados de estado y de actividad con la morfología de imperfecto. Tal como proponen los expertos en aspecto léxico (Morimoto, 1998; De Miguel, 1999; Marín, 2001) para distinguir predicados télicos de atélicos usamos los complementos temporales encabezados por en y durante respectivamente, como ya hemos visto anteriormente. Con el verbo sonar podemos decir El teléfono sonó durante una hora pero no *Sonó en una hora, lo mismo sucede con crujir, como se observa en Las puertas crujieron durante unos minutos pero no *Las puertas crujieron en un minuto. Además, el imperfecto crujían implica crujieron, así como sonaban implica sonaron, como propone Morimoto para averiguar qué predicados verbales son atélicos. En resumidas cuentas, y en contra de lo deseable, como estamos viendo, todos los verbos son atélicos.

En definitiva, muchos de estos ejemplos servirán a nuestros alumnos de estímulo para validar la hipótesis según la cual el aspecto léxico télico se corresponde con el indefinido mientras que el atélico se corresponde con el imperfecto. El mismo manual propone ejemplos como estos otros:

(29) Expresa acciones y estados realizados en el pasado pero no concluidos:

- En aquellos tiempos era muy caro.

- En verano pasábamos las vacaciones en Salou.

- Antes leía mucho.

- De niño jugaba en ese parque.

La aplicación de las pruebas habituales para decidir el aspecto léxico al que pertenecen estos predicados nos dan nuevamente predicados atélicos, aunque en algunos casos, la estructura argumental del verbo podría modificar el aspecto léxico como es el caso de leer. Se pone de manifiesto la necesidad de una taxonomía adecuada que ayude al docente a diseñar actividades que manipulen adecuadamente la noción de aspecto léxico.

Estos son algunos otros ejemplos que ponen de manifiesto que el input al que exponemos a nuestros aprendices en las aulas es decisivo a la hora de ralentizar o disparar las fases por las que inconscientemente van a pasar hasta interiorizar el uso apropiado de la morfología 
verbal del español. Mientras los aprendices alcanzan la competencia lingüística en relación con la morfología verbal, los docentes debemos tener en cuenta que no es deseable que cuando explicamos el imperfecto en clase, tan solo les demos ejemplos de esta marca morfológica con verbos atélicos, como vemos en (29).

A favor de muchos de los materiales ya diseñados, debemos decir que en muchos manuales de nivel intermedio observamos ejemplos contextualizados y actividades didácticas centradas en la función de los dos pretéritos en contextos narrativos. Si bien es cierto que muchos textos presentan verbos de todo tipo, también lo es que se echa de menos una alusión directa al hecho de que cualquier tipo de verbo, con independencia de su significado, puede llevar cualquier marca de morfología verbal. Falta explicitar la independencia del aspecto léxico en el uso de la morfología verbal en las explicaciones que se da a los estudiantes. Es más, como ya hemos dicho, creemos que es necesario explicitar el concepto de aspecto léxico y de diferenciarlo del aspecto gramatical. Sobre todo, y a la luz de los experimentos llevados a cabo hasta el momento, se hace necesario explicitar que cualquier verbo puede llevar cualquier marca morfológica de pasado siempre y cuando haya concordancia entre los elementos que componen la oración.

También, se echa de menos el uso de la imagen como facilitadora de los múltiples significados asociados a una y otra marca verbal. Son muchas las voces que indican que contextualizar los ejemplos a través de las imágenes parece ser una de las herramientas más útiles en la enseñanza de idiomas. Sería interesante proponerles a los alumnos narraciones utilizando tanto verbos télicos como atélicos, presentándoles vídeos o viñetas que luego tendrían que completar con la correspondiente narración. Para ello, el docente debería asegurarse de que la historieta fuera rica en matices y exigiera el uso de verbos de todo tipo. Sería igualmente interesante pedirles la misma actividad a un grupo de nativo hablantes del español y posteriormente dejar que los aprendices contrastaran su narración con la del hablante nativo. El grupo de nativo hablantes le serviría al profesor como grupo de control que le asegurara que la producción tanto oral como escrita efectivamente resultara esclarecedora a la hora de distinguir aspecto léxico y aspecto gramatical. De igual forma, la producción de los nativo hablantes le permitiría al docente evidenciar el hecho de que el aspecto léxico no se corresponde con el aspecto gramatical en el uso real de la lengua. De esa manera, las narraciones de nativo hablantes del español le pueden servir al docente como muestra para los propios aprendices. Este parece ser un buen camino para facilitar al alumno la interiorización del buen uso de la distinción indefinido/imperfecto.

En relación con la explotación de las imágenes en el aula, en la actualidad se están llevando a cabo interesantes proyectos que explotan precisamente la distinción teórica aspecto léxico/aspecto gramatical, además del uso de las nuevas tecnologías, en el diseño de materiales para el aula de español. Uno de estos proyectos es el Tutor del Aspecto Verbal (Chiquito y Munera, 2005). Chiquito y Munera dicen que este proyecto «tiene como objetivo visualizar el aspecto verbal ${ }^{2}$ en vídeo a través de cortas secuencias narrativas y de actividades prácticas construidas sistemáticamente según el aspecto léxico y verbal de los verbos usados en ella» (Chiquito y Munera, 2005: 1). No nos extenderemos aquí en esta cuestión, pero sí remitimos al lector interesado en esta metodología de enseñanza del aspecto que acuda a las fuentes bibliográficas donde podrá observar los detalles de este trabajo, sin duda prometedor.

2 Aspecto verbal significa aquí lo mismo que aspecto gramatical. 
Para finalizar, debemos señalar que, además de las consideraciones didácticas que acabamos de ver, saber de las diferentes etapas por las que pasa el aprendiz en su proceso de adquisición de la morfología verbal también debe tener consecuencias en la evaluación que hacemos de la competencia lingüística de nuestros alumnos. Si bien los exámenes nos sirven para averiguar en que punto de la adquisición del aspecto gramatical están los aprendices, las correcciones en sus redacciones y ensayos deben ser concienzudamente analizadas antes de ser emitidas. En algunas ocasiones puede ser demasiado apresurado corregir algo que, como estamos viendo, se adquiere de forma natural, no se aprende a través de la instrucción formal. Nuestra evaluación como docentes debe servir para disparar los procesos de adquisición de la morfología verbal y no sólo para penalizar los errores.

\section{Conclusiones}

Dada la especial relevancia que en las últimas décadas han tenido las categorías de aspecto gramatical y aspecto léxico en los estudios de adquisición de segundas lenguas tanto a nivel teórico como a nivel experimental, hemos revisado en este trabajo tanto las propuestas teóricas como las recientes hipótesis propuestas en torno a dichas categorías. La revisión de una y otra vertiente han puesto de manifiesto la relevancia de la categoría semántica de aspecto en las diferentes fases de adquisición de la morfología verbal, especialmente la adquisición de las marcas morfológicas de indefinido e imperfecto.

Si bien, la aparente ausencia de marcas explícitas de aspecto gramatical en español llevó a los gramáticos tradicionales a no prestar atención a esta categoría, los estudios de tipologías de lenguas nos han llevado a retomar los estudios en relación con el aspecto considerado no tan solo como una categoría gramatical sino como una categoría semántica en cuyo cálculo intervienen el lexema verbal, los morfemas flexivos, los complementos verbales y la función discursiva que desempeñe el enunciado resultante. En relación con este complejo puzzle del aspecto, y preocupados por la demora manifiesta en el buen uso que los aprendices de español hacen de la morfología verbal, muchos investigadores de adquisición de segundas lenguas han diseñado múltiples experimentos con el objetivo final de entender qué factor aspectual interviene en la adquisición de la morfología verbal.

De los múltiples análisis hasta el momento realizados, se desprende una importantísima hipótesis que no debe pasar inadvertida para ninguno de los profesores de español como segunda lengua, a saber, en las primeras fases de adquisición el aprendiz manifiesta una clara tendencia a confiar el uso de la morfología verbal en relación con el contenido léxico del verbo que utiliza, de tal manera que un verbo télico (logro, realización) aparecerá preferiblemente con el pretérito indefinido en un primer momento y más tarde también con verbos atélicos (actividad, estado), mientras que en fases posteriores el aprendiz comenzará a usar el pretérito imperfecto con verbos atélicos y finalmente con verbos télicos.

$\mathrm{Si}$ en las fases iniciales del proceso de adquisición de la morfología verbal, además de la mencionada hipótesis de la primacía del aspecto léxico, también parece tener relevancia la hipótesis del tiempo por defecto, esto es, el uso inicial del indefinido con valor temporal, en las fases finales del proceso de adquisición toma especial importancia la hipótesis del aspecto discursivo, de tal manera que el aprendiz tendrá en cuenta si sus enunciados forman parte del fondo o del foco a la hora de seleccionar el imperfecto o el indefinido, respectivamente. Si esto es así, parece obvio que el docente debe tener en cuenta esta estrategia desde las primeras 
etapas, presentando datos de verbos que contravengan esa «creencia inconsciente» de que los predicados atélicos van solo con el imperfecto y los télicos solo con el indefinido.

En resumidas cuentas, todos estos hallazgos acerca de la adquisición de la morfología verbal deben ser tenidos en cuenta por el profesor a la hora de llevar materiales al aula para el aprendizaje de las marcas morfológicas verbales. El concepto de aspecto léxico debe ser explicitado tanto en nuestras explicaciones gramaticales como en los ejercicios que les proponemos a los aprendices. Asimismo, el diseño de ejercicios de gramática debería tener en cuenta la consideración de que a falta de contextualización incluso el hablante nativo de español tiende a asociar el aspecto léxico con el aspecto gramatical (Güell, 2008). Así pues, los ejercicios de gramática propuestos en el aula de español, además de concienzudamente diseñados teniendo en cuenta el aspecto léxico de los verbos seleccionados, deberían aparecer debidamente contextualizados: Si no se contextualiza el uso del contraste indefinido/ imperfecto exponemos a nuestros alumnos a un input que los puede mantener en un nivel de interlengua por más tiempo del deseado.

\section{Referencias bibliográficas}

Álvarez, E. (2005): «Aprender a narrar: formas temporales y sus funciones en un niño de siete a nueve años de edad». Barcelona English Language and Literature Studies, 1: http://www.publicacions. ub.es/revistes/bells14/ (30-9-2009)

Andersen, R. (1986): «El desarrollo de la morfología verbal en el español como segundo idioma». En J. M. Meisel (ed.): Adquisición de lenguaje: Aquisição da linguagem. Frankfurt, Vervuert, págs. 115-138.

Ayoun, D. y Salaberry, R. (2005): Tense and Aspect in Romance Languages: Theoretical and Applied Perspectives. Amsterdam/Philadelphia, John Benjamins.

Bardovi-Harlig, K. (1998): «Narrative structure and lexical aspect: Conspiring factors in second language acquisition of tense-aspect morphology». Studies in Second Language Acquisition 20, págs. 471-508.

Bello, A. (1981): Gramática de la lengua castellana destinada al uso de los americanos, estudio y edición de Ramón Trujillo. Madrid, Arco/ Libros.

Chiquito, B. y Munera Sánchez, M. (2008): «Tutor del Aspecto Verbal». RedELE: Actas del II Congreso de la Asociación Noruega de Profesores de Español: Multiculturalidad y norma policéntrica: Aplicaciones en el aula de ELE: http://www.educacion.es/redele/Biblioteca2009/Noruega2008. shtml_(30-9-2009)

De Miguel, E. (1999): «El aspecto léxico». En Bosque, I. y Demonte V. (dirs.): Gramática descriptiva de la lengua española. Madrid, Espasa, págs. 2977-3061.

Díaz, L. y Bekiou, K. (2006): «Lo que las reformulaciones y repeticiones (halladas en los relatos orales) de los aprendices de español L2 pueden decirnos acerca de la adquisición del aspecto verbal en español». En Milka Villayandre Llamazares (ed.): Actas del XXXV Simposio Internacional de la Sociedad Española de Lingüistica, págs. 400-418.

García Fernández, L. (1998): El aspecto gramatical en la conjugación. Madrid, Arco/ Libros.

González, P. (2005): «Distribución de los morfemas de aspecto gramatical en interlenguaje». En Bob de Jonge (ed.) Estudios de Lingüística del Español: Actas del II Congreso de la Región Noroeste de Europa de la Asociación de Lingüística y Filología de América Latina, 22: http://elies.rediris.es/ elies22/index.htm (30-9-2009) 
Güell, L. (2008): «El reconocimiento de la naturaleza composicional del aspecto en la adquisición del español como lengua extranjera». En Olza Moreno I., Casado Velarde M. y González Ruiz R.(eds.): Actas del del XXXVII Simposio Internacional de la Sociedad Española de Lingüistica. Pamplona, Servicio de Publicaciones de la Universidad de Navarra: http://www.unav.es/linguis/simposiosel/ actas/ (30-9-2009)

Hasbún, L. (1995): The role of lexical aspect in the acquisition of the tense/aspect system in L2 Spanish. Tesis doctoral inédita, Indiana University, Bloomington.

Hopper, P. J. (1982): «Aspect between discourse and grammar». En P. J. Hopper (ed.): Tense-Aspect: Between semantics and pragmatics. Typological Studies in Language 1. Amsterdam/Philadelphia, John Benjamins, págs. 3-19.

Labov, W. (1972): Sociolinguistic patterns. Philadelphia, University of Pennsylvania Press.

Lafford, B. (1996): «The development of tense/aspect relations in L2 Spanish narratives: Evidence to test competing theories». Presentado en Second Language Research Forum, University of Arizona, Tucson.

Marín, R. (2001): El componente aspectual en la predicación. Tesis doctoral inédita. Universidad Autónoma de Barcelona: http://dialnet.unirioja.es/servlet/tesis?codigo $=4283$.

Matte Bon, F. (1992): Gramática comunicativa del español. Madrid, Difusión.

Morimoto, Y. (1998): El aspecto léxico: Delimitación. Madrid, Arco/ Libros.

Rojo, G. y Veiga, A. (1999): «El tiempo verbal. Los tiempos simples». En Bosque, I. y Demonte V. (dirs.): Gramática descriptiva de la lengua española. Madrid, Espasa, págs. 2867-2935.

Salaberry, R. y Shirai, Y. (2002): Tense-Aspect Morphology in L2 acquisition. Language Acquisition and Language Disorders. Amsterdam, The Netherlands: John Benjamins.

Salaberry, R. (2003): «Tense aspect in verbal morphology». Hispania 83, 3, págs. 559-573.

Vendler, Z. (1967): Linguistics in Philosophy. Ithaca, Cornell University Press.

Tenny, C. (1988): «The aspectual interface hypothesis: the connection between syntax and lexical semantics». En C. Tenny (ed.) Studies in Generative Approaches to Aspect. Lexicon Project Working Papers, 24, Center for Cognitive Science. MIT, Cambridge, Mass., págs. 1-18.

Verkuyl, H. (1972): On the Compositional Nature of the Aspect, Foundations of Language Supplementary Series, XV. Dordrecht, Reidel.

Von Stutterheim, C. y Klein, W. (1989): «Referential movement in descriptive and narrative discourse». En R. Dietrich y C. Graumann (eds.) Language Processing in Social Context. Holland, Elsevier Science Publishers B. V. 